\title{
ANALISIS KESALAHAN KONSEP MAHASISWA CALON GURU FISIKA PADA MATERI KINEMATIKA MENGGUNAKAN TES DIAGNOSTIK THREE TIER
}

\author{
Alfrie Musa Rampengan, Kristanto Gunawan Kumonong, Anneke Tinneke Rondonuwu, \\ Fakultas Matematika dan Ilmu Pengetahuan Alam, Universitas Negeri Manado \\ email: kkumonong@gmail.com
}

\begin{abstract}
ABSTRAK
Miskonsepsi adalah cara pandang salah dalam memahami suatu peristiwa yang terjadi. Berbagai jenis penelitian juga telah dilakukan guna mengungkap dan menyelesaikan permasalahan miskonsepsi ini. Penelitian ini bertujuan untuk menganalisis miskonsepsi Mahasiswa Calon Guru Fisika (MCGF) pada konsep kinematika. Dengan bentuk penelitian kualitatif, teknik pengambilan data dilakukan menggunakan tes diagnostik three tier adapun uji keabsahan data menggunakan bahan referensi yaitu rekap tes berupa naskah hasil tes diagnostik three tier. Analisis data dilakukan dengan cara diuraikan, dikategorikan, disintesiskan, lalu diurutkan secara sistematis dengan menggunakan tiga langkah yaitu peredaksian, penyajian, dan penarikan kesimpulan/verifikasi. Dari penelitian yang dilakukan, diperoleh hasil bahwa miskonsepsi yang terjadi pada MCGF mayoritas pada subkonsep Gerak Lurus Berubah Beraturan (GLBB) dan Gerak Parabola khususnya dalam menentukan lintasan proyektil. Faktor penyebab terjadinya miskonsepsi yakni pikiran asosiatif, reasoning yang tidak lengkap bahkan cenderung salah, dan intuisi yang keliru. Adapun alternatif penyelesaian yang dapat dilakukan adalah menghadapkan responden pada kenyataan, peristiwa anomali, dan rasionalitas serta untuk reasoning yang kurang lengkap dan keliru agar segera dilengkapi. Diharapkan permasalahan miskonsepsi yang terjadi dapat segera diperbaiki.
\end{abstract}

Kata kunci : Miskonsepsi, Mahasiswa, Kinematika, Tes Diagnostik Three tier.

\begin{abstract}
Misconception is a wrong way of looking at an event that occurs. Various types of research have also been conducted to uncover and resolve these misconceptions. This study aims to analyze the misconceptions of the Physics Teacher Candidate Student (MCGF) on the concept of kinematics. With the form of qualitative research, the data collection technique was carried out using a threelevel diagnostic test while the validity of the data used reference material, namely a test recap in the form of a three-level diagnostic test result script. Data analysis was carried out by being described, categorized, synthesized, then sorted systematically using three steps, namely editing, presenting, and drawing conclusions. From the researc, the results show that the misconceptions that occur in MCGF are determined by the sub-concept of Regularly Changing Straight Motion (GLBB) and Parabolic Motion, especially in determining the projectile trajectory. Factors that cause misconceptions are associative thoughts, incomplete reasoning and even tend to be wrong, and wrong intuition. An alternative solution that can be done is exposing the respondent to recovery, anomalous events, and incomplete and erroneous rationality and reasoning so that it is immediately completed. It is hoped that any misconceptions that occur can be immediately contacted.
\end{abstract}

Keywords : Misconceptions, Students, Kinematics, Three Tier Diagnostic Test 


\section{PENDAHULUAN}

Fisika merupakan bidang ilmu yang membimbing kita untuk memahami fenomena fisis dalam kehidupan sehari-hari melalui model matematis dalam kegiatan saintifik (Grusche, 2019). Jika kita telaah, fisika pada hakekatnya menuntut adanya proses pembelajaran yang efektif dan efisien yakni pembelajaran yang dapat dilaksakan secara optimal. Pendidik dituntut untuk mampu mendorong peserta didik dalam membangun pengetahuan, dengan tuntutan ini tentu pemahaman konsep yang baik merupakan tujuan yang harus benar-benar dicapai oleh seorang pendidik. Fakta dilapangan menunjukan bahwa pemahaman konsep fisika yang dimiliki pendidik bahkan calon pendidik dalam hal ini mahasiswa calon guru fisika masih sangat kurang. Ismu Wahyuni dalam Jurnal Penelitiannya yang berjudul Pemahaman Konsep dan Miskonsepsi Fisika pada Guru Fisika SMA RSBI di Bandar Lampung menemukan bahwa tingkat pemahaman konsep mekanika oleh guru fisika SMA RSBI Bandar Lampung hanyalah 42\% (Wahyuni, 2013).

Mahasiswa program studi pendidikan fisika sebagai calon guru atau pendidika di bidang fisika setidaknya dibekali dengan pemahaman konsep yang benar menurut para ahli fisika dan tidak mengandung kesalahan pemahaman. Jika terdapat kesalahan pemahaman sejak awal tentu akan memberikan penularan kesalahan konsep kepada peserta didik mereka kelak. Kesalahan konsep terdapat dalam semua bidang sains seperti biologi, kimia, fisika, dan astronomi. Dari 700 studi mengenai konsep alternatif bidang fisika, ada 300 yang meneliti tentang kesalahan konsep dalam mekanika, 159 tentang listrik, 70 tentang panas, optik dan sifat-sifat materi, 25 tentang bumi dan antariksa, serta 10 studi mengenai fisika modern (Suparno, 2005) dalam data ini menunjukan bahwa mekanika merupakan bidang fisika yang paling banyak mengalami kesalahan konsep. Novak "mendefinisikan kesalahan konsep sebagai interpretasi konsepkonsep dalam suatu pernyataan yang tidak dapat diterima" (dikutip dalam Suparno 2005). Penyebab kesalahan konsep antara lain siswa/mahasiswa, guru/dosen, buku/diktat, konteks, dan metode mengajar. Kesalahan konsep perlu diketahui dan dihilangkan agar terjadi pembelajaran yang sistematis dan terarah. Kinematika sendiri merupakan bagian dari mekanika dan merupakan bidang fisika yang paling banyak mengalami kesalahan konsep (Suparno 2005 : 11). Uraian mengenai permasalahan mengenai permasalahan dari diri guru dan konsep-konsep yang kerap kali menimbulkan kesalahan pemahaman sangatlah penting untuk di analisis dalam kaitanya untuk meningkatkan kompotensi pendidik khususnya fisika. Penelitian ini bertujuan untuk mengetahui terjadi atau tidaknya kesalahan konsep pada mahasiswa calon guru fisika khususnya pada program studi pendidikan fisika universitas negeri manado pada materi kinematika, mengetahui letak miskonsepsi yang dialami mahasiswa calon guru fisika pada khususnya pada konsep kinematika, menemukan faktor penyebab kesalahan konsep yang dialami mahasiswa calon guru fisika, dan menentukan alternatif penyelesaian masalah kesalahan pemahan konsep yang dialami mahasiswa calon guru fisika.

Kesalahan konsep sendiri merujuk pada ketidaksesuaian dengan perngertian ilmuan yang diterima parak di bidang yang dipelajari (Suparno, 2005). Dikutip dalam suparno (2005) novak mendefinisikan kesalahan konsep/miskonsepsi sebagai suatu interpretasi konsep-konsep dalam suatu pernyataan yang tidak dapat diterima. Ada beberapa alat untuk mendeteksi dan mengungkapkan kesalahan konsep yakni peta konsep, tes multiple choice dengan reasoning terbua, tes essai tertulis, diskusi dalam kelas, dan praktikum dengan tanya jawab. Tentu saja kesalahan konsep harus diketahui dan dihilangkan agat terjadi pembalajaran yang bermakna secara sistematis.

Adapun beberapa tes diagnostik yang digunakan dalam mengidentifikasi kesalahan konsep peserta didik dan salah satunya ialah tes diagnostik three tier. Tes diagnostik three tier merupakan pengembangan dari tes diagnostik two tier yang tersusun dari tiga tingkatan jawaban soal. Tingkatan pertama berupa pilihan jawaban, tingkat kedua berupa alasan, dan tingkat ketiga berupa pertanyaan penegasan tentang keyakinan dari jawaban yang telah dipilih pada tingkat pertama dan tingkat kedua (Syahrul dan Seyarsih 2015). Tes diagnostik three tier sendiri merupakan tes yang dikombinasikan dengan certainly respons index (CRI), CRI adalah salah satu metode untuk membedakan kesalahan konsep/miskonsepsi dengan tidak tahu konsep. Dengan metod CRI, responden diminta untuk memberikan tingkat 
kepastian dari kemampuan mereka sendiri dengan mengasosiasikan tingkat keyakinan tersebut dengan pengetahuan, konsep, atau hukum (Hasan dkk. 1999). Dengan memperhatikan kondisi kategori tingkat pemahaman yang disusun oleh Hasan dkk (1999) maka Hakim dkk (2012) dalam jurnal penelitiannya yang berjudul "Student Concept Understanding of Nature Product Chemistry in Primary and Secondary CRI" memodifikasi dengan menambahkan alasan terbuka yang melalui teknik ini pendidik dapat menganalisis pemahaman peserta didik secara lebih objektif.

\section{METODE PENELITIAN}

Jenis penelitian ini merupakan jenis penelitian kualitatif (Qualitative reasearch) yang ditujukan demi mendeskripsikan dan menganalisis fenomena, peristiwa, sikap, kepercayaan, dan pemikiran seseorang secara individual atau kelompok. Penelitian ini dilaksanakan pada semester ganjil tahun ajaran 2020/2021 kepada 10 orang sampel mahasiswa program studi pendidikan fisika semester III dengan asumsi setiap mahasiswa/sample sudah memahami secara baik mekanika khususnya sub bagian kinematika sebagai bahan penelitian.

Fokus penelitian adalah mahasiswa program studi pendidikan fisika angkatan 2019, instrument penelitian yang digunakan untuk mengidentifikasi kesalahan konsep adalah tes diagnostik three tier, dan materi yang diujikan adalah konsep kinematika. Fakus penelitian ini bertujuan untuk membatasi peneliti sehingga terhindar dan terjebak dalam pengumpulan data pada bidang yang sangat umum dan luas atau kurang relevan dengan perumusan masalah dan tujuan penelitian.

Tes diagnostik three tier sendiri disusun dalam dua tahap yakni tahap revisi (reviton) yang dimaksudkan untuk meninjau keseluruhan kelayakan dan kesamaan makna serta saransaran guna penyempurnaan instrumen penelitian ini kemudian tahap pertimbangan (judgement) dilakukan untuk mempertimbangkan tiap-tiap subkonsep yang ada pada instrument. Setelah kedua tahap tersebut selesai maka instrumen tes diagnostik three tier harus divalidasi oleh validator guna menilai apakah instrumen ini valid dan layak digunakan atau tidak.

Keabsahan dari data penelitian ini di uji menggunakan bahan referensi yakni alat pendukung untuk membuktikan data telah ditemukan berupa naskah hasil tes diagnostik three tier yang telah di ujikan.

Teknik analisis data meliputi tiga tahapan (menurut Moleong \& Lexy, 2007) yakni reduksi data menjadi satu bentuk tulisan (script) yang akan di analisis dan kemudian dilakukan identifikasi terhadap mahasiswa yang mengalami kesalahan konsep, tidak tahu konsep, dan menguasai konsep dengan baik. Tahap berikutnya adalah penyajian data yang merupakan sekumpulan informasi yang diberikan guna penarikan kesimpulan dan penarikan tindakan. Dan yang terakhir adalah verifikasi atau penarikan kesimpulan guna menjawab pertanyaan pada tujuan peneltian.

\section{HASIL DAN PEMBAHASAN}

Bagian ini dibagi menjadi Validasi Instrument Tes Diagnostik Three Tier, Data Hasil Tes Diagnostik Three Tier dan Analisis Data Hasil Penelitian.

Validasi Instrument Tes Diagnostik Three Tier dilakukan oleh dua orang validator yang dianggap memiliki kompetensi dibidangnya masing-masing. Adapun instrument tes diagnostik three tier dinilai berdasarkan rubrik penilian tes diagnostik three tier. Hasil validasi insrument tes diagnostik three tier oleh kedua validator dapat dilihat secara garis besar pada tabel 1

Tabel 1 Hasil Validasi Instrument Tes Diagnostik Three Tier.

\begin{tabular}{|c|c|c|c|c|}
\hline \multirow[t]{2}{*}{ No } & \multirow[t]{2}{*}{ Kriteria Peniliaian } & \multicolumn{2}{|c|}{ Skor Penilai } & \multirow[t]{2}{*}{ Skor Total } \\
\hline & & Ahli 1 & Ahli 2 & \\
\hline & Aspek Petunjuk Instr & men & & \\
\hline \multirow[t]{2}{*}{1} & 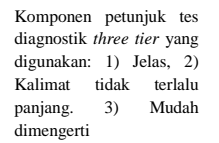 & 4 & 4 & 8 \\
\hline & Aspek Isi Instrumen & & & \\
\hline 2 & $\begin{array}{l}\text { Kesamaan makna soal } \\
\text { pada instrument asli dan } \\
\text { terjemahan }\end{array}$ & 3 & 3 & 6 \\
\hline 3 & Keterbacaan soal & 4 & 4 & 8 \\
\hline \multirow[t]{2}{*}{4} & $\begin{array}{l}\text { Kejelasan } \\
\text { keberfungsian } \\
\text { gambar/diagram }\end{array}$ & 4 & 4 & 8 \\
\hline & Aspek Bahasa Instru & & & \\
\hline 5 & $\begin{array}{l}\text { Komponen bahasa yang } \\
\text { digunakan: 1) Jelas, 2) } \\
\text { Mudah dipahami, 3) } \\
\text { komunikatif }\end{array}$ & 4 & 3 & 7 \\
\hline 6 & $\begin{array}{l}\text { Kesesuaian dengan } \\
\text { kaidah bahasa indonesia }\end{array}$ & 4 & 3 & 7 \\
\hline \multirow[t]{2}{*}{7} & Penafsiran bahasa & 4 & 4 & 8 \\
\hline & Aspek Konstruksi Ins & umen & & \\
\hline 8 & $\begin{array}{l}\text { Komponen tata letak } \\
\text { penyusunan: 1) Memiliki }\end{array}$ & 3 & 3 & 6 \\
\hline
\end{tabular}




\begin{tabular}{lllll}
\hline \multicolumn{5}{l}{ kesatuan dan konsistensi } \\
berdasarkan sub konsep, \\
2) terstruktur, 3) \\
Proporsional
\end{tabular}

Instrument tes diagnostik three tier setelah melalui proses validasi oleh dua orang validator ahli yang menyatakan layak untuk dipergunakan tanpa revisi selanjutnya digunakan sebagai alat untuk menguji pemahaman responden agar diketahui apakah terjadi kesalahan konsep atau tidak dan apabila terdapat kesalahan konsep maka dapat diketahui pula terjadi kesalahan konsep pada subkonsep apa saja.

Hasil Tes Diagnostik Three Tier yang diujikan kepada 10 (sepuluh) mahasiswa calon guru fisika selanjutnya disebut MCGF semester III. Hasil tes diagnostik ini dinilai berdasarkan tabel modifikasi kategori tingkatan pemahaman responden. Hasil dari uji tes diagnostik three tier kepada kesepuluh MCGF dapat dilihat secara umum pada tabel 2 .

Tabel. 2 Hasil Tes Diagnostik Three Tier Keadaan Konsepsi MCGF

\begin{tabular}{|c|c|c|c|c|c|c|c|c|c|c|}
\hline 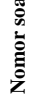 & 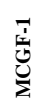 & 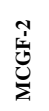 & 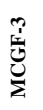 & 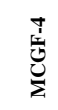 & 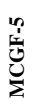 & 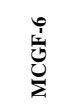 & 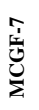 & 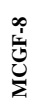 & 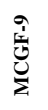 & 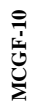 \\
\hline 1 & PK & PK & $M$ & PK & PK & $\begin{array}{c}\text { PPK } \\
Y\end{array}$ & PK & $M$ & TTK & $M$ \\
\hline 2 & PK & PK & M & M & PK & $\begin{array}{c}\text { PPK } \\
Y\end{array}$ & $M$ & $\mathrm{M}$ & M & $M$ \\
\hline 3 & M & $M$ & TTK & $M$ & $M$ & $\begin{array}{c}\text { PPK } \\
Y\end{array}$ & $M$ & $\mathrm{M}$ & M & $M$ \\
\hline 4 & $M$ & TTK & M & PK & $M$ & $\begin{array}{c}\text { PPK } \\
Y\end{array}$ & PK & $\mathrm{M}$ & M & $M$ \\
\hline 5 & $M$ & $M$ & $M$ & $M$ & $M$ & $\begin{array}{c}\text { PPK } \\
Y \\
\end{array}$ & PK & $\mathrm{M}$ & $\mathrm{M}$ & $M$ \\
\hline 6 & $M$ & M & M & PK & $M$ & $\begin{array}{c}\text { PPK } \\
\mathrm{Y} \\
\end{array}$ & $\mathrm{M}$ & M & M & $M$ \\
\hline 7 & PK & PK & $M$ & TTK & $M$ & $\begin{array}{c}\text { PPK } \\
Y \\
\end{array}$ & $M$ & $M$ & PK & $M$ \\
\hline 8 & PK & PK & $M$ & $M$ & $M$ & TTK & $M$ & TTK & $M$ & TTK \\
\hline 9 & $M$ & PK & $M$ & TTK & $M$ & $\begin{array}{c}\text { PPK } \\
Y \\
\end{array}$ & $M$ & $M$ & PK & TTK \\
\hline $\begin{array}{l}1 \\
0\end{array}$ & PK & PK & M & TTK & $\mathrm{M}$ & TTK & $\mathrm{M}$ & TTK & M & TTK \\
\hline $\begin{array}{l}1 \\
1 \\
\end{array}$ & $\mathrm{M}$ & $M$ & $M$ & TTK & $M$ & TTK & $M$ & TTK & $M$ & TTK \\
\hline $\begin{array}{l}1 \\
2 \\
\end{array}$ & PK & PK & TTK & $\begin{array}{c}\text { PPK } \\
Y\end{array}$ & $M$ & TTK & $M$ & $M$ & $M$ & TTK \\
\hline
\end{tabular}

\begin{tabular}{lllllllllll}
\hline 1 & PK & PK & M & TTK & PK & PPK & PK & M & M & TTK \\
3 & & & & & & Y & & & & \\
\hline 1 & M & M & M & TTK & PK & TTK & M & M & PK & M \\
4 & & & & & & & & & & \\
\hline 1 & PK & M & M & TTK & TTK & TTK & M & TTK & M & M \\
5 & & & & & & & & & & \\
\hline
\end{tabular}

Keterangan :

$$
\begin{array}{lll}
\text { PK } & : & \text { Paham Konsep } \\
\text { PKKY } & : & \text { Paham Konsep Namun Kurang Yakin } \\
\text { M } & : & \text { Miskonsepsi } \\
\text { TTK } & : & \text { Tidak Tahu Konsep }
\end{array}
$$

Dari tabel 2 dapat kita lihat bahwa keadaan pemahaman mahasiswa calon guru fisika (MCGF) pada materi kinematika hampir secara keseluruhan mengalami kesalahan konsep/miskonsepsi.

Analisi kemudian dilakukan kepada ke-10 Mahasiswa Calon Guru Fisika yang telah di uji menggunakan tes diagnostik three tier dan didapati bahwa sebagai besar penyebab terjadinya kesalahan konsep kepada mahasiswa calon guru fisika berada pada tingkat keyakinan saat memilih jawaban pada tes diagnostik three tier yang melebihi 2,5 (CRI > 2,5) pada tier ketiga yang secara tidak langsung menandakan bahwa responden memiliki keyakinan yang tinggi mengenai jawaban pada tier pertama dan tier kedua padahal mengalami dan terindikasi terjadi kesalahan. Selain itu ditemukan juga bahwa responden ternyata hanya memahami konsep secara parsial (tidak menyeluruh) tanpa memahami dan mendalami kembali secara utuh hingga menyebabkan responden mengalami kesulitan dalam menentukan jawaban yang tepat saat menjawab soal yang diujikan pada tes diagnostik three tier. Hal ini lah yang banyak memicu responden mengalami responden. Dengan demikian dapat disimpulkan bahwa faktor penyebab terjadinya kesalahan konsep/miskonsepi oleh mahasiswa calon guru fisika berasal dari pikiran asosiatif, reasonning yang kurang lengkap, dan intuisi yang keliru.

Alternatif yang dapat lakukan oleh pendidik dalam hal ini dosen adalah menghadapkan mahasiswa calon guru fisika pada kenyataan, peristiwa anomali, dan rasionalitas serta reasoning guna membangun gagasan dan konsep yang benar dalam memahami konsep-konsep yang ada pada kinematika.

\section{KESIMPULAN}

Kesimpulan yang diambil dari hasil analisis data adalah bahwa terjadi kesalahan konsep kepada mahasiswa calon guru fisika pada konsep kinematika dan terungkap dengan 
menggunakan instrument tes diagnostik three tier.

Kesalahan konsep yang terjadi dialami oleh hampir seluruh mahasiswa calon guru fisika (MCGF) selain MCGF-6 dan sebagian besar terjadi pada subkonsep GLBB serta gerak parabola khususnya pada penentuan lintasan.

Faktor utama yang menjadi penyebab terjadinya kesalahan konsep kepada mahasiswa calon guru fisika (MCGF) adalah diri mereka sendiri yakni pemikiran asosiatif, reasonning yang tidak lengkap, dan intuisi yang salah saat menentukan dan memberikan alasan pada tes diagnostik three tier.

Alternatif yang bisa digunakan oleh pendidik untuk menyelesaikan pemahaman konsep yang keliru oleh mahasiswa calon guru fisika (MCGF) antara lain dihadapkan kepada peristiwa anomali, dihadapkan pada kenyataan, dan diajarkan kembali sesuai dengan level perkembangan masing - masing MCGF guna membangun kembali pemahaman yang tepat mengenai konsep kinematika dan diajarkan.

\section{REFERENSI}

Alwi, dkk. 2003. Kamus Besar Bahasa Indonesia Edisi ketiga, Cet Ke-13. Jakarta: Balai Pustaka

Hakim, Liliasari, \& Kadarohman. 2012. Student Concept Understanding of Nature Product Chemistry in Primary and Secondary CRI, International Online Journal of Educational Sciences, 4(3), 544-553:1309-2707.

Hasan, S. D. Bagayako, D. \& Kelley, E. L. 1998. Misconceptions and the Certainly Response Index (CRI). Phys. Educ, 34(5).

Moleong \& Lexy J. 2007. Metodologi Penelitian Kualitatif. Bandung : Remaja Rosdakarya.

Grusche, S. 2019. Phenomenon-based Learning and Model-based Teaching: Do They Match?. Journal of Physics: Conference Series, 1287(1).

Suparno. 2005. Miskonsepsi dan Perubahan Konsep dalam Pendidikan Fisika. Jakarta : PT Grasindo

Wahyuni, I. 2013. Pemahaman Konsep Miskonsepsi Fisika Pada Guru Fisika SMA RSBI di Bandar Lampung. Jurnal Pendidikan MIPA Universitas Lampung, 14(1), 121125. 